\title{
Pengaruh E-learning berbasis Edmodo pada Mata Kuliah Pengantar Sistem dan Teknologi Informasi
}

\author{
Ismail \\ Program Studi Informatika, Fakultas Teknik, Universitas Sulawesi Barat \\ E-mail: ismailmajid@unsulbar.ac.id
}

\begin{abstract}
Abstrak
Tugas utama sebagai seorang dosen adalah mencakup 3 hal yakni melakukan pengajaran, penelitian, dan pengabdian masyarakat. Terkadang akibat adanya tugas selain pengajaran, dosen tidak maksimal memberikan perkuliahan di ruang kelas. Selain itu, untuk melakukan penjadwalan ulang perkuliahan tidak mudah karena terbatasnya ruang kelas yang tersedia. Penelitian ini bertujuan mengungkapkan perbedaan hasil belajar mahasiswa yang diajar dengan metode e-learning berbasis edmodo dengan metode diskusi. Penelitian ini merupakan penelitian Quasi eksperimen mengggunakan Randomized Solomon Four-Group Design, dengan meneliti empat kelompok mahasiswa yaitu kelas eksperimen yang terdiri dari satu kelompok yang ikut pretest dan satu kelompok tidak ikut pretest dan kelas kontrol juga terdiri dari dua kelompok satu kelompok ikut pretest dan kelompok satu berikutnya tidak ikut pretest. Kelas eksperimen diberikan perlakuan dengan menggunakan e-learning berbasis edmodo dan kelompok kontrol diberikan perlakuan menggunakan pembelajaran dengan metode diskusi. Hasil penelitian menunjukkan hasil belajar mahasiswa yang diajar menggunakan metode e-learning berbasis edmodo masuk pada kategori tinggi atau dengan presentase sebesar 57\%. Terdapat perbedaan rata-rata nilai hasil belajar antara kelas eksperimen dengan kelas kelas kontrol akan tetapi tidak signifikan.
\end{abstract}

Kata kunci - e-Learning, edmodo, sistem informasi

\begin{abstract}
The main task as a lecturer is to cover 3 things such as teaching, research, and community dedication. Sometimes due to additional tasks other than teaching, lecturers do not optimally provide lectures in classrooms, and to do rescheduling of the lecture is not easy because of the limited classrooms available. This study reveals differences in the results of research students taught by edmodo-based e-learning methods with discussion methods. This research is a Quasi experimental study using the Random Solomon Solomon Four-Group Design, by examining groups of students who study research consisting of one group participating in a pretest and one group did not take part in the pretest and the control class also consisted of two groups, one group took the pretest and the next group did not take the pretest. Experimental classes are given using e-learning based on Edmodo and the control group is given using learning with discussion methods. The results showed the learning outcomes of students taught using the e-learning method based on Edmodo included in the high category with a percentage of 57\%. There is difference in the average value of learning outcomes in the experimental class with the control class but not insignificant.
\end{abstract}

Keywords - e-Learning, edmodo, information system 


\section{PENDAHULUAN}

Sistem pembelajaran jarak jauh telah diatur dalam Peraturan Pemerintah No 17 Tahun 2010 bagian Bab VI tentang penyelenggaraan pendidikan jarak jauh pada Pasal 118. Pendidikan jarak jauh bertujuan meningkatkan perluasan dan pemerataan akses pendidikan, serta meningkatkan mutu dan relevansi pendidikan.

Program studi Informatika merupakan prodi yang ada dilingkup Fakultas Teknik Universitas Sulawesi Barat yang secara resmi mendapat surat izin pada bulan November 2013. Salah satu mata kuliah yang ada pada prodi informatika adalah pengantar sistem dan teknologi informasi, bobot mata kuliah 2 sks yang bersifat teoritis, sangat memungkinkan melakukan model pembelajaran diskusi baik diskusi secara konvensional maupun diskusi menggunakan media elektronik $(e-$ learning)

Tugas utama sebagai seorang dosen adalah mencakup 3 hal yakni melakukan pengajaran, penelitian, dan pengabdian masyarakat. Ketiga tugas pokok tersebut dibagi dalam porsi masingmasing. Terbatasnya ruang kelas hampir menjadi permasalahan setiap dosen dalam memaksimalkan perkuliahan. Secara ideal, tatap muka perkuliahan dalam satu semester adalah 16 kali pertemuan. Adanya kegiatan lain selain pengajaran terkadang membuat dosen pengampuh mata kuliah tidak maksimal dalam memberikan perkuliahan secara langsung. E-learning (daring) merupakan salah satu cara agar bisa memaksimalkan jumlah tatap muka perkuliahan atau dalam bentuk pemberian tugas secara daring.

Edmodo merupakan sosial media yang secara tampilan mirip dengan facebook dan merupakan salah satu jejaring belajar sosial terbesar di dunia yaitu sebesar 31.633.951 juta pengguna siswa dan guru (https://www.edmodo.com, 2014) [1] yang dapat digunakan sebagai media pembelajaran secara elearning. Dengan data pengguna edmodo yamg besar tersebut peneliti tertarik untuk mencoba eksperimen untuk mengetahui pengaruh penggunaan edmodo sebagai e-learning terhadap hasil belajar mahasiswa pada prodi informatika.

\section{METODE PENELITIAN}

\subsection{Jenis Penelitian}

Penelitian ini merupakan penelitian Quasi eksperiment dengan meneliti empat kelompok mahasiswa yaitu kelas eksperimen yang terdiri dari satu kelompok yang ikut pretest dan satu kelompok tidak ikut pretest dan kelas kontrol juga terdiri dari dua kelompok satu kelompok ikut pretest dan kelompok satu berikutnya tidak ikut pretest. Kelas eksperimen diberikan perlakuan dengan menggunakan e-learning berbasis edmodo sedangkan kelompok kontrol diberikan perlakuan menggunakan pembelajaran dengan metode diskusi. 


\subsection{Subjek Penelitian}

Subjek dalam penelitian ini adalah mahasiswa Program Studi Informatika Universitas Sulawesi Barat semester Gasal (I) tahun ajaran 2018-2019.

\subsection{Tempat Penelitian}

Penelitian ini dilaksanakan pada semester gasal tahun ajaran 2018-2019 di Universitas Sulawesi Barat .

\subsection{Instrumen Penelitian}

Instrument berupa lembar tes mahasiswa yang digunakan untuk mengetahui tingkat penguasaan materi pembelajaran pada mata kuliah pengantar sistem dan teknologi informasi. Tes ini dilakukan pada akhir pembelajaran di kelas eksperimen dan kelas kontrol.

\subsection{Teknik Pengumpulan Data}

Cara yang digunakan untuk mengumpulkan data adalah dengan memberikan tes hasil belajar berupa soal-soal materi perkuliahan pengantar sistem dan teknologi informasi dalam bentuk pilihan ganda. Tes ini diberikan kepada mahasiswa setelah pembelajaran e-learning berbasis edmodo pada kelas eksperimen dan metode diskusi pada kelas kontrol.

\subsection{Desain Penelitian}

Penelitian ini mengggunakan Randomized Solomon Four-Group Design. Desain ini dapat mengurangi kelemahan validitas eksternal (external validity) dan validitas internal (internal validity) yang ada pada Randomized Control Group Pretest Postest [2].

\begin{tabular}{|cccc|}
\hline $\mathbf{R}:$ & $\mathrm{T}_{1}$ & $\mathbf{X}$ & $\mathrm{T}_{2}$ \\
$\mathbf{R}:$ & $\mathrm{T}_{3}$ & $\mathbf{K}$ & $\mathrm{T}_{4}$ \\
\hline $\mathbf{R}:$ & & $\mathbf{X}$ & $\mathrm{T}_{5}$ \\
$\mathbf{R}:$ & & $\mathbf{K}$ & $\mathrm{T}_{6}$ \\
\hline
\end{tabular}

Gambar 1. Desain Solomon four- group Design (Suryabrata, 2013)

\section{Keterangan}

$\mathrm{R}=$ Kelompok dipilih secara random (acak)

$\mathrm{X} \quad=$ Kelompok eksperimen pertama (perlakuan e-learning edmodo)

$\mathrm{K} \quad=$ Kelompok kontrol (perlakuan diskusi)

$\mathrm{T}_{1} \quad=$ pretest kelompok eksperimen pertama

$\mathrm{T}_{2} \quad=$ postest $\mathrm{kelompok}$ eksperimen pertama

$\mathrm{T}_{3} \quad=$ pretest kelompok kontrol pertama

$\mathrm{T}_{4} \quad=$ posttest kelompok kontrol pertama

$\mathrm{T}_{5} \quad=$ posttest kelompok eksperimen kedua 


\subsection{Teknik Analisis Data}

Teknik analisis data yang dugunakan untuk menganalisis hasil belajar dalam penelitian ini menggunakan teknik analisis statistik deskriptif diolah menggunakan program statistic SPSS for Windows release 20.

\section{HASIL DAN PEMBAHASAN}

\subsection{Deskripsi Hasil Penelitian}

Data hasil penelitian berupa skor Mahasiswa/ responden dari hasil belajar terdiri dari dua kelas yaitu kelas A Teknik Informatika dengan jumlah Mahasiswa sebanyak 39 orang, dan kelas B Teknik Informatika dengan jumlah Mahasiswa sebanyak 37 orang. Kelas A Teknik Informatika adalah kelas eksperimen sedangkan kelas B adalah sebagai kelas kontrol. Masing-masing kelas dibagi dua kelompok yaitu kelompok pretest dan kelompok non pretest. Data yang yang diperoleh dari hasil penelitian adalah berupa skor-skor atau nilai yang terdiri dari data awal (pretest) dan data akhir (posttest) atau hasil belajar dari dua kelas yaitu kelas eksperimen dan kelas control. Deskripsi data keadaan awal hasil pretest mahasiswa kelas A dan B disajikan dalam bentuk Tabel 1 dan chart pada Gambar 2.

Tabel 1 Keadaan Awal Skor Pretest Mahasiswa Kelas A dan B

\begin{tabular}{|c|c|c|}
\hline & PretestKelasA & PretestKelasB \\
\hline Valid & 20 & 19 \\
\hline Missing & 0 & 1 \\
\hline Mean & 56,48 & 54,97 \\
\hline Std. Error of Mean & 2,827 & 2,184 \\
\hline Median & 56,60 & 53,30 \\
\hline Mode & 57 & 53 \\
\hline Std. Deviation & 12,643 & 9,519 \\
\hline Variance & 159,833 & 90,606 \\
\hline Skewness &, 104 & ,452 \\
\hline Std. Error of Skewness &, 512 &, 524 \\
\hline Kurtosis &,- 878 & ,482 \\
\hline Std. Error of Kurtosis & ,992 & 1,014 \\
\hline Range & 41 & 38 \\
\hline Minimum & 37 & 37 \\
\hline Maximum & 78 & 75 \\
\hline Sum & 1130 & 1044 \\
\hline
\end{tabular}




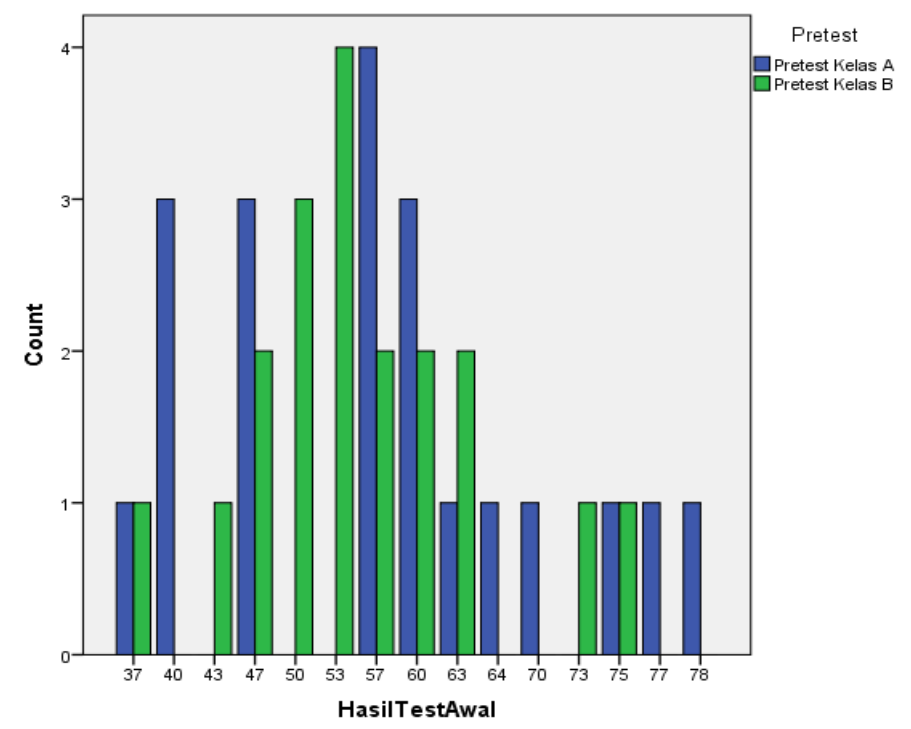

Gambar 2. Bar Charts Keadaan Awal Skor Pretest Mahasiswa Kelas A dan B

Setelah proses pembelajaran e-learning berbasis edmodo dilaksanakan pada kelas eksperimen maka semua kelompok pretes dan non pretest akan diberi tes akhir (posttest) demikian halnya pada kelas kontrol juga akan diberi posttest setelah mahasiswa diajar dengan metode diskusi. Berdasarkan dari hasil penelitian yang diolah menggunakan program SPSS 20 dengan analysis of variance diperoleh bahwa kelas yang menggunakan e-learning berbasis edmodo (kelas eksperimen) setelah dilakukan postest memperoleh hasil belajar dengan rata - rata (mean) 68.86, standard deviation 11.205, sedangkan kelas yang menggunakan metode diskusi (kelas kontrol) setelah dilakukan postest memperoleh hasil belajar dengan rata-rata (mean) 67,31 dengan standard deviation 8,647. Hasil tersebut dapat dilihat pada Tabel 2 dan Gambar 3.

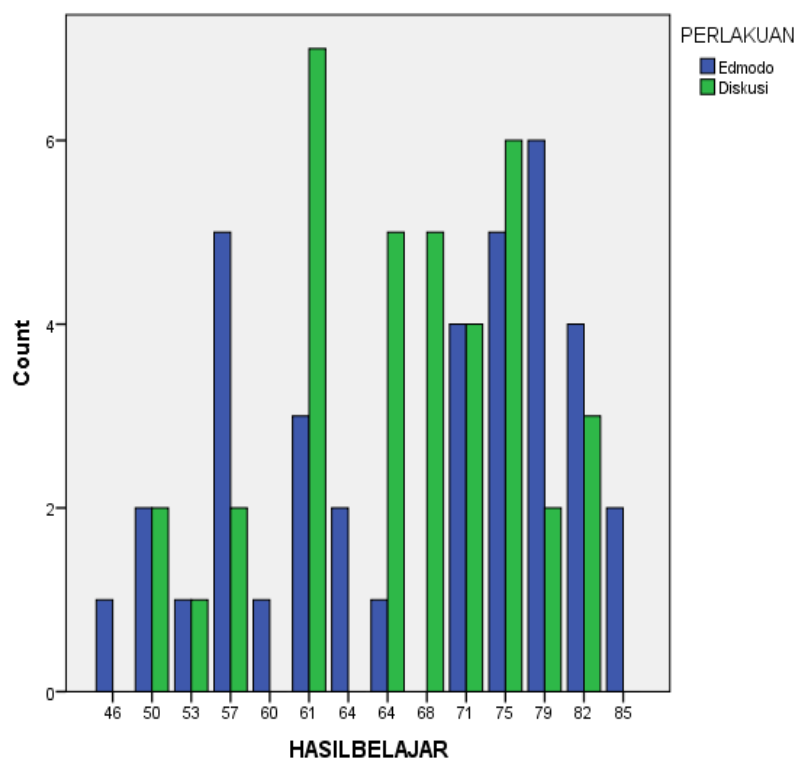

Gambar 3 Perbandingan Skor posttest Kelas Eksperimen dengan Kelas Kontrol 
Tabel 2 Perbandingan skor hasil belajar metode-learning berbasis edmodo dengan metode diskusi

\begin{tabular}{lccc}
\hline & PosttestEdmodo & PosttestDiskusi \\
\cline { 2 - 2 } $\mathrm{N}$ & \multicolumn{1}{c}{ Valid } & 37 & 37 \\
\cline { 2 - 3 } Mean & 0 & 0 \\
Std. Error of Mean & 68,86 & 67,31 \\
Median & 1,842 & 1,422 \\
Mode & 71,40 & 67,80 \\
Std. Deviation & 79 & 61 \\
Variance & 11,205 & 8,647 \\
Skewness & 125,543 & 74,767 \\
Std. Error of Skewness &,- 340 &,- 107 \\
Kurtosis &, 388 &, 388 \\
Std. Error of Kurtosis & $-1,136$ &,- 619 \\
Range &, 759 &, 759 \\
Minimum & 39 & 32 \\
Maximum & 46 & 50 \\
Sum & 85 & 82 \\
\hline
\end{tabular}

\subsection{Pengujian Hipotesis}

Berdasarkan hasil analisis data dengan menggunakan program SPSS diperoleh output pertama jumlah data yang valid untuk perlakuan edmodo ada 37 orang dan perlakuan diskusi 37 orang serta tidak ada data missing. Pengujian hipotesis dimaksudkan untuk membuktikan hipotesis bahwa ada perbedaan hasil belajar yang signifikan antara Mahasiswa yang diajar menggunakan metode $e$ learning berbasis edmodo dengan metode diskusi pada mata pelajaran pengelolaan informasi. Hipotesis yang ingin diuji dalam pengujian ini adalah:

Ho: Tidak ada perbedaan hasil belajar yang signifikan antara mahasiswa yang diajar menggunakan metode e-learning berbasis edmodo dengan metode diskusi pada mata kuliah pengantar sistem dan teknologi informasi

H1: Ada perbedaan hasil belajar yang signifikan antara mahasiswa yang diajar menggunakan metode $e$-learning berbasis edmodo dengan metode diskusi pada mata kuliah pengantar sistem dan teknologi informasi

Kriteria penerimaan dan penolakan Ho

Ho diterima jika signifikansi $\geq \alpha$

Ho ditolak jika signifikansi $\leq \alpha$

Dengan tingkat signifikansi $\alpha=5 \%$ 
Hasil pengujian yang dilakukan dengan menggunakan proram SPSS 20 dengan teknik pengujian Independent Sample T Test untuk mengetahui rata - rata perbedaan antar dua kelompok dalam hal ini perbedaan nilai hasil belajar kelas A (kelas eksperimen) dengan menggunakan metode e-learning berbasis edmodo dengan hasil belajar kelas B (kelas kontrol) dengan menggunakan metode diskusi, dan diperoleh hasil output nilai sig sebesar 0.507 yang berarti lebih besar dari nilai sig. $\alpha(0,05)$, maka Ho di terima. Dengan demikian tidak terdapat perbedaan hasil belajar yang signifikan antara mahasiswa yang diajar metode e-learning berbasis edmodo dengan metode diskusi walaupun secara statistik deskriptif nilai rerata kelas A (kelas eksperimen) yang diberi metode pembelajaran berbasis edmodo lebih tinggi dibanding dengan kelas B (kelas kontrol) yang diberi metode pembelajaran diskusi

\section{KESIMPULAN}

Hasil belajar siswa yang diajar menggunakan metode e-learning berbasis edmodo mayoritas berada pada kategori tinggi. Secara statistik deskriptif terdapat perbedaan rata-rata nilai hasil belajar antara kelas A (kelas eksperimen) yang menggunakan metode $e$-learning berbasis edmodo dengan kelas B (kelas kontrol) menggunakan metode diskusi akan tetapi perbedaan tersebut tidak signifikan.

\section{REFERENSI}

Andi Kristanto, 2011. Pengembangan Model Media Video Pembelajaran Mata Kuliah Pengembangan Media Video/Tv Program Studi Teknologi Pendidikan Fakultas Ilmu Pendidikan Universitas Negeri Surabaya (Online) Vol. 11 No. 1 (http://jurnal-teknologipendidikan.tp.ac.id, di akses 12 Juni 2014)

Ariesto, 2012. Teknologi Informasi dan Komunikasi dalam Pendidikan. Yogyakarta: Graha Ilmu Arsyad , A. 2011. Media Pembelajaran. Jakarta: PT. Raja Grafindo Persada.

Bambang Warsita, 2011. Pendidikan Jarak Jauh. Bandung: PT Remaja Rosdakarya Undang-Undang Guru Dan Dosen. (2009). Yogyakarta: PUSTAKA PELAJAR. http://www.upi.edu/agenda/id/95/Workshop-Pembelajaran-Abad-21. (2013, Januari). (2014, 6 Februari kamis). Retrieved from https://www.edmodo.com.

Arismunandar. (2006). Manajemen Pendidikan Peluang Dan Tantangan. Makassar: Universitas Negeri Makassar.

Bona. (2011, 05 05). Retrieved from http://edukasi.kompasiana.com.

Djoyonegoro. (1998). Pengembangan Sumber Daya Manusia Melalui Pendidikan Menengah Kejuruan. Jakarta: Jaya Agung Offset.

Hamzah B. Uno. (2012). Belajar Dengan Pendekatan PAILKEM (Pembelajaran Aktif Inovatif Lingkungan Kreatif Efektif Menarik. Jakarta: Bumi Aksara.

Mulyasa. (2002). Bandung: PT Remaja Rosdakarya.

Munir. (2009). Pembelajaran Jarak Jauh Berbasis Teknologi Informasi dan Komunikasi. Bandung: Alfabeta.

Nizhamiyah Kasim. (2013). Efektivitas Pembelajaran Sistem Jaringan Komputer menggunakan Cisco Packet Tracer Jurusan Teknik Komputer Jaringan pada SMKN 1 Minasatene Pangkep. Makassar: Universitas Negeri Makassar. 
Purwanto. (2011). Evaluasi Hasil Belajar. Yogyakarta: Pustaka Pelajar.

Sagala. (2009). Konsep Dan Makna Pembelajaran. Bandung: ALFABETA.

Sofan Amri. (2013). Pengembangan \& Model Pembelajaran dalam Kurikulum 2013. Jakarta:

Prestasi Pustaka.

Sudjana. (2010). Bandung: Remaja Rosdakarya.

Sugiyono. (2011). Metode penelitian Pendidikan . Bandung: ALFABETA. 